\title{
Task instructions as a determiner of the GSR index of the orienting reflex
}

\author{
IRVING MALTZMAN, JAY GOULD, MARY PENDERY, and CRAIG WOLFF \\ University of California, Los Angeles, California
}

\begin{abstract}
Twelve college students in each of three groups were instructed to (1) sit quietly and listen while innocuous words and an occasional tone were heard, (2) covertly think pleasant thoughts whenever they heard a tone, or (3) perform an overt pedal response whenever they heard a tone. Twenty different neutral words were presented prior to the tone. Habituation of the GSR induced by these different words varied significantly as a function of the task instructions. Pedal group students displayed mean magnitude GSRs significantly larger than those of the control group. Think group students did not differ significantly from either of the two remaining groups. Basal conductance levels did not differ significantly among the three groups, which indicates that differences in the phasic GSR cannot be attributed to differences in arousal level. An interpretation of the results was offered in terms of the orienting reflex (OR) and its predeterminers.
\end{abstract}

Stimulus significance, or the signal value of stimuli, has long been recognized as a determiner of the orienting reflex (OR) by Soviet investigator (Feigenberg, 1969; Latash, 1968; Luria \& Vinogradova, 1969; Sokolov, 1963). More recently, it has begun to receive the attention among Western investigators that its importance warrants (e.g., Bernstein, 1979; Maltzman, 1979; O'Gorman, 1979; Van Olst, 1971). Despite some exceptions (e.g., Barry, 1978), studies usually report that stimulus significance is a powerful and robust variable. It can readily be demonstrated by the introduction of task instructions following an initial phase of habituation. It was this paradigm, as exploited by Luria and Vinogradova (1959), that first attracted our attention to the importance of the OR in general and to stimulus significance in particular (Maltzman \& Raskin, 1965).

Luria and Vinogradova (1959) reported that the repeated presentation of innocuous words resulted in habituation of the digital vasomotor measure of the OR. However, if a particular word was given signal

\footnotetext{
This study was made possible in part by funds provided by U.S. Public Health Service Research Grant MH 04684 and by the Carnegie Corporation of New York. For the analyses of the results of the experiment reported here, computing assistance was obtained from the Health Science Computing Facility, University of California, Los Angeles, which was sponsored by National Institutes of Health Grant FR-3. Jay Gould is now at the University of West Florida; Mary Pendery is at the San Diego Veterans Administration Hospital; and Craig Wolff is now at International Rehabilitation Associates, Incorporated. Requests for reprints should be sent to Irving Maltzman, Department of Psychology, University of California, Los Angeles, California 90024.
}

value and the subject was instructed to press a button whenever a particular word was presented, responsivity to that word increased. Semantic generalization of the OR to related words also occurred. Maltzman \& Raskin $(1965,1979)$ replicated and extended the Luria and Vinogradova (1959) study by including covert as well as overt task instructions to respond to a particular word. A between-subject design was employed so that the differential responding of the experimental participants with respect to the critical and neutral filler words could be compared with the responsivity of a control group not instructed to respond to any word. Maltzman and Raskin (1979) demonstrated that covert as well as overt task instructions resulted in a highly significant differential responsivity to the critical stimulus word following a period of habituation. Responsivity to the noncritical words in the experimental group was not greater than that in the control group, which indicates that selective orienting was involved. There was no general overall increase in responsivity, an increase that could have been attributed to a nonspecific effect such as arousal. Results of this kind demonstrating that signal value of stimuli heightens and prolongs the responsivity of measures of the OR can be accounted for in several different ways. Increasingly popular interpretations in terms of information processing can be applied to these results, as well as to a variety of other psychophysiological phenomena (e.g., Bernstein, 1979). A simpler interpretation, one that we prefer and that is in keeping with a Pavlovian approach to phenomena relating to orienting and conditioning, is available. It requires no new concepts and is rather obvious. Task instructions that impart significance to a stimulus result in heightened orienting to those stimuli because the response sub- 
sequently evoked by the significant stimulus is a manifestation of a verbally conditioned OR (Maltzman, 1979; Pendery \& Maltzman, 1977).

A second important result obtained in the Maltzman and Raskin (1965) study has generally been overlooked in theoretical discussions of stimulus significance and the OR. It has important implications for the kind of theoretical interpretation necessary to account for the phenomena of stimulus significance. Experimental groups instructed to respond covertly or overtly to a particular word showed greater responsivity to all words than did the control group prior to the appearance of the first task stimulus. One obvious interpretation of these results is that experimental participants simply displayed a heightened level of arousal as a consequence of the impending task and therefore were more responsive to all stimuli than were the control group (O'Gorman, 1979). However, conductance level, a commonly employed index of arousal, did not differ significantly among the experimental and control groups.

The present paper reports the results of a study that attempted to replicate and extend previously reported results (Maltzman \& Raskin, 1965, 1979). Results reported here were obtained from the habituation phase that preceded a semantic conditioning experiment that examined overt and covert activity in a forewarned reaction time situation designed to induce a UCR with innocuous stimuli (Maltzman, Gould, Pendery, \& Wolff, 1977). Maltzman and Raskin (1979) instructed students to respond overtly, or covertly, to a specific word among many, or simply to listen to words. In the present study, experimental students were instructed either to overtly or covertly respond to a tone interspersed among words or simply to listen to words and an occasional tone.

\section{METHOD}

\section{Subjects}

Thirty-six students (18 men and 18 women) from introductory psychology classes served in the experiment. Participation in the experiment was a means of partially fulfilling a course requirement.

\section{Procedure}

All students were told to sit quietly and listen carefully to a series of words and tones that they would hear. Each student had the electrodes explained to him or her, and each was told that we were interested in studying the physiological correlates of relaxation. Each Pedal group student was also instructed to lift his or her foot as fast as possible from the pedal upon which it was resting whenever he or she heard the tone. Each Think group student was instructed to free associate pleasant thoughts whenever he or she heard the tone. Control group students were simply told to sit quietly and listen. There were 12 students, 6 men and 6 women, in each of the three principal groups.

All students were presented with a series of 20 different neutral words that had been prerecorded on magnetic tape and were heard via stereophonic headphones. Words were selected from the
Thorndike and Lorge (1944) high-frequency word list. Interword intervals varied from 12 to $18 \mathrm{sec}$. Intensity of the words was approximatley $60 \mathrm{~dB}(\mathrm{~A})$. No tones were presented during this habituation phase of the experiment. The conditioning that followed this habituation session has been described elsewhere (Maltzman et al., 1977).

\section{Apparatus}

The experimental arrangement and recording system has been previously described (Maltzman et al., 1977). Briefly, the GSR was recorded by bipolar palmar electrodes consisting of two $20-\mathrm{mm}$ disk electrodes fitted into 5-mm-deep plastic cups. The cups were filled with electrode paste made from agar and $1 \%$ zinc sulfate solution and were attached to the palms of the hands by plastic pressure clips. Recording was accomplished using a 40- $\mu \mathrm{A}$ Wheatstone bridge and one channel of a Sanborn $320 \mathrm{dc}$ amplifierrecorder. An event marker recorded the occurrence of each word on the polygraph record. Paper speed was $1 \mathrm{~mm} / \mathrm{sec}$. The GSR measure employed was the largest resistance change occurring within .5-10 sec after the presentation of a stimulus. Prior to analysis, the GSR measure was transformed to a log conductance change score. Log conductance base level at the time each stimulus was presented was also determined. The .05 level of significance for a two-tailed test was adopted in all statistical analyses.

\section{RESULTS AND DISCUSSION}

Within each of the three groups the students were categorized within sexes as high and low orienters on the basis of their mean GSRs to the 12 tone presentations that occurred in the subsequent conditioning phase.

Figure 1 shows the mean magnitude of the GSRs evoked in the three groups by the 20 different words prior to the presentation of the tones and the performance of the task for which they had been instructed. It is apparent that, while the three groups did show habituation (a response decrement with successive words), the groups differed in the magnitudes of their GSRs. Analyses of variance and orthogonal polynomials yielded a significant effect for OR

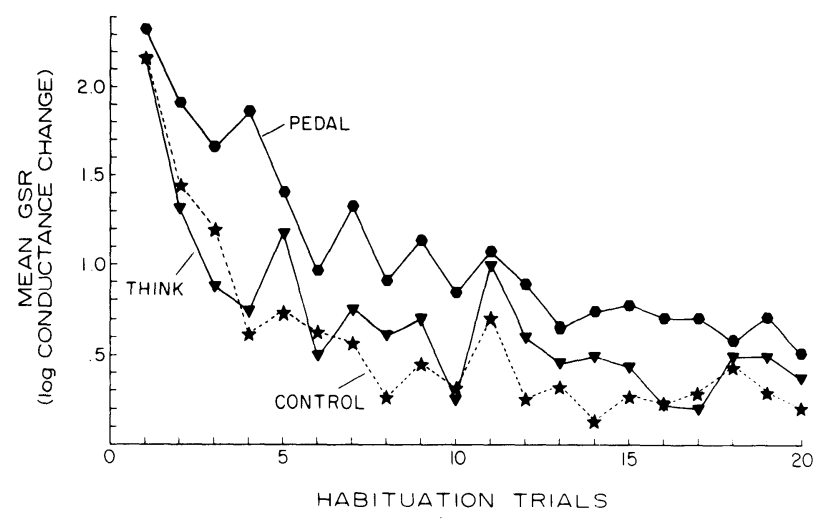

Figure 1. Mean GSRs induced by different words in control and experimental groups prior to the occurrence of the task, response to a tone. Participants in the Think group were instructed to covertly associate to a tone; Pedal participants were instructed to overtly respond to a tone; Control participants were instructed to sit quietly and listen. 
level $[F(1,24)=11.18]$, groups $[F(2,24)=4.23$, $\left.\mathrm{MS}_{\mathrm{B}}=3.92\right]$, and trials $[\mathrm{F}(19,456)=31.17, \mathrm{MSW}=$ .255]. Specific comparisons indicated that the responsivity of the Pedal group was significantly greater than that of the Control group $[F(1,24)=$ 8.12], but the Think group did not differ significantly from either the Pedal or the Control group.

Examination of log conductance level measured at the time of occurrence of each word indicated that there was a significant trend during the course of habituation. Trials was a significant main effect $\left[\mathrm{F}(19,627)=49.9, \mathrm{MS}_{\mathrm{W}}=.270\right]$. An analysis of orthogonal polynomials indicated a significant mean linear trend in the declining conductance level $[\mathrm{F}(1,33)=58.75, \mathrm{MSe}=.409]$. Most pertinent to our present concern was the finding that the three groups did not differ significantly in mean conductance levels. Think, Pedal, and Control groups obtained mean log conductance levels of 2.98, 2.87, and 2.77, respectively. Likewise, groups did not enter into any significant interactions. Thus, differences in mean magnitudes of the phasic GSR as a consequence of task instructions could not be attributed to differences in a nonspecific variable such as arousal as measured by basal conductance level. O'Gorman's (1979) hypothesis that stimulus significance may be accounted for, in part, in terms of arousal was contradicted by these results.

The present results differed in two respects from those that previously had been obtained (Maltzman \& Raskin, 1965, 1979). First, the present task instructions asked students to respond to a tone interspersed among words. Instructions used by Maltzman and Raskin (1979) asked students to respond to a word interspersed among other words. Results from the present experiment therefore indicated that the heightened responsivity to words induced prior to the first appearance of a tone was not specific to the signal described in the task instructions or to members of the same class of stimuli as the signal.

A second difference from the Maltzman and Raskin (1979) study was that instructions to covertly respond heightened responsivity in the latter experiment but did not significantly increase responsivity prior to performance in the present experiment, although the obtained difference was in the predicted direction. Other than the possibility that the smaller number of students employed in the present experiment yielded a less powerful test of the hypothesis, we have no ready explanation for the failure to replicate the effect of covert activity.

Finally, it must be noted that analysis of variance indicated that the three groups did not differ in the magnitude of their GSRs to the first word presented. Differences among the groups developed as habituation progressed, as had been the case in previous experiments (Maltzman, Gould, Barnett, Raskin, \& Wolff, 1979; Maltzman \& Raskin, 1979). As previously indicated (Maltzman, 1977), we assume that, prior to the first stimulus, the students were maximally uncertain as to what would happen and when it would happen. After the occurrence of several words in the habituation series, the situation became more predictable, and various attitudes, sets, or anticipations may have come into play. Complex integrative cortical processes may then have modified subsequent $O R s$ and thus produced different amounts and rates of habituation of the GSRs. We assume that an initial, relatively unexpected novel stimulus evoked a relatively involuntary OR reflected as a GSR, but that subsequent, increasingly predictable stimuli evoked a relatively voluntary $O R$.

It remains necessary to explain heightened ORs as manifested by increased magnitude of the GSRs to stimuli in the absence of increased novelty and nonspecific arousal. Historically, these results might be explained in terms of set and attention. Task instructions produced an Aufgabe, or determining tendency, a set for the tone. As a consequence, there was an increased tendency to selectively attend and respond to certain stimuli and not to others (Humphrey, 1951; Titchener, 1909). Again, historically, notions of set and of attention have been intimately related (Paschal, 1941). Set refers to a relatively persistent or long-standing disposition to respond in a particular way, whereas attention refers to a phasic tendency to differentially respond. Repeated attending to a given stimulus may result in the establishment of a set, and a set increases the likelihood of attending to particular stimuli.

Implications of conceptions of set and attention find their counterparts in psychophysiological theories of the dominant focus and the OR, respectively (Maltzman, 1979; Pendery \& Maltzman, 1979; Wingard \& Maltzman, 1980). Task instructions, we assume, induce a dominant focus that selectively influences the transmission of information in the central nervous system. Increases in a dominant focus as the result of afferent input may give rise to manifestations of an OR. Physiological measures of dominant foci are available through the use of Livanov's (1977) electroencephaloscopic technique along with measures of the OR, such as the GSR. In an experiment similar to the present one, we would predict that the use of the electroencephaloscope would reveal an increase in synchronous EEG activity, given particular task instructions, activity that would be further increased when stimuli were presented, particularly the relevant stimulus. Presentations of these stimuli not only increase cortical excitability, but they also induce ORs reflected as GSRs.

\section{REFERENCES}

BARRY, R. J. Physiological changes in a reaction time task: Further problems with Sokolov's dimension of stimulus "significance." Physiological Psychology, 1978, 6, 438-444.

Bernstein, A. S. The orienting reflex as novelty and signif- 
icance detector: Reply to O'Gorman. Psychophysiology, 1979, 16, 263-273.

Feigenberg, I. M. Probabilistic prognosis and its significance in normal and pathological subjects. In M. Cole \& I. Maltzman (Eds.), A handbook of contemporary Soviet psychology. New York: Basic Books, 1969.

Humphrey, G. Thinking. London: Methuen, 1951.

LATASH, L. P. Hypothalamus, adaptive activity, and the electroencephalogram. Moscow: Nauka, 1968.

Livanov, M. N. Spatial organization of cerebral processes. New York: Wiley, 1977.

Luria, A. R., \& Vinogradova, O. S. An objective investigation of the dynamics of semantic systems. British Journal of Psychology, 1959, 50, 89-105.

Maltzman, I. Orienting in classical conditioning and generalization of the GSR to words: An overview. Journal of Experimental Psychology: General, 1977, 106, 111-119.

Maltzman, I. Orienting reflexes and significance: A reply to O'Gorman. Psychophysiology, 1979, 16, 274-282.

Maltzman, I., \& Raskin, D. C. Effects of individual differences in the orienting reflex on conditioning and complex processes. Journal of Experimental Research in Personality, 1965, 1, 1-16.

Maltzman, I., \& RAskin, D. C. Selective orienting and habituation of the GSR as a consequence of overt and covert activity. Physiological Psychology, 1979, 7, 204-208.

Maltzman, I., Gould, J., Barnett, O. J., Raskin, D. C., \& WoLFF, C. Habituation of the GSR and digital vasomotor components of the orienting reflex as a consequence of task instructions and sex differences. Physiological Psychology, $1979,7,213-220$.
Maltzman, I., Gould, J., Pendery, M., \& Wolff, C. Semantic conditioning and generalization of the GSR orienting reflex with overt and covert activity. Journal of Experimental Psychology: General, 1977, 106, 172-184.

O'Gorman, J. G. The orienting reflex: Novelty or significance detector? Psychophysiology, 1979, 16, 253-262.

Paschal, F. C. The trend in theories of attention. Psychological Review, 1941, 48, 383-403.

Pendery, M., \& Maltzman, I. Instructions and the orienting reflex in "semantic conditioning" of the galvanic skin response in an innocuous situation. Journal of Experimental Psychology: General, 1977, 106, 120-140.

Pendery, M., \& Maltzman, I. Verbal conditioning and extinction of the GSR index of the orienting reflex. Physiological Psychology, 1979, 7, 185-192.

Sokolov, E. N. Perception and the conditioned reflex. New York: Macmillan, 1963.

Thorndike, E. L., \& LoRge, I. The teacher's word book of 30,000 words. New York: Bureau of Publications, Columbia University, Teachers College, 1944.

Titchener, E. B. Lectures on the experimental psychology of the thought-processes. New York: Macmillan, 1909.

Van Olst, E. H. The orienting reflex. The Hague: Mouton, 1971.

Wingard, J. A., \& Maltzman, I. Interest as a predeterminer of the GSR index of the orienting reflex. Acta Psychologica, $1980,46,153-160$.

(Manuscript received December 5, 1980; revision accepted for publication May 14, 1982.) 